\title{
Influencia de la Historia y el Paisaje, en la Vida y Obra de Fabio Luz
}

\author{
I \\ Prelusión
}

$\mathrm{E}^{\mathrm{N}}$ la noche tormentosa de la historia, agobiado por el peso de los siglos en que había surgido una vigorosa cultura que diera al mundo luces y estableciera entre dos continentes separados por la garganta de dos mares ubérrimos en pugna por establecer contacto, vagaba el sarraceno a través de la estepa castellana, acosado por la fuerza bárbara de unos hombres destemidos, sobre caballos que galopaban al encuentro de un nuevo destino que se presentaba ante sus ojos con la presencia de la fe. Avanzaban resueltos y, a su paso, encandilados por la magnificencia de una civilización que decaía, iban dejando una estela luminosa en que brillaran siglos de historia perdida, asombro de un mundo que no sabía leer. Partía de allí un ciclo de historia nueva que había de empujar a Europa hacia un destino que cristalizaríase más tarde en una tremenda revolución intelectual y mecánica.

El último sarraceno, que había quemado la pureza de su raza en aquel suelo, fuera él también precursor de la era que se iniciaba. Aun sin reconocerlo, venía alimentando el fuego de aquel destino que iba a trastornar el equilibrio occidental. $Y$ fué merced a su incomprensión, a la carencia del contacto con los pueblos occidentales por lo que los sucesores en ideas no podrían menos que seguir, a la larga, la trayectoria de la cultura arábiga de que está saturada hasta en su misma esencia el cuerpo y alma ibéricos. Era el choque 
de dos mundos que se encontraban y que hiciera explosión en la arremetida del vástago aún sin cultivar, pero que, lejos de ocasionar la desaparición de uno de los contendientes, a la larga se fusionarían, dando un producto límpido, puro, sano, to más acabado de Europa.

Al lado de la estepa, un pueblo de hombres intrépidos, agitado por las ideas de un visionario que diera un mundo al mundo, no han podido resistir el contacto de la sin igual proeza que empequeñecía la gloria del hombre sobre la tierra. $\mathrm{Y}$ alrededor de una bandera legada en tratos amorosos, trabajaban y cultivaban con cariño las glorias y hazañas de otros hombres que, unidos en un afán de sorpresa, formaron el triángulo ibérico. Hasta el nombre de su pueblo tiene olor a poesía. Y para emular la gloria de aquellos hombres que en frágiles embarcaciones rompieran la corteza del mar y navegaran sobre las ruinas de la Atlántida misteriosa, sepultada bajo las aguas, también los lusiadas, a través de generaciones, empinaron la proa de sus naves hacia el sur del Atlántico con sus terribles misterios, agudizados por el descubrimiento del nuevo continente. Temerarios cual sus hermanos de la otra orilla del Tajo, alimentados por la savia de una misma civilización, cuna del renacimiento europeo, lanzáronse a la aventura para romper las ligaduras en que se encontraban aprisionados y para ir ensanchando la corteza de la tierra en la que no cabía su grandeza espiritual, y abrían, en un abrir y cerrar de ojos, rutas desconocidas para el ingenio y caminos por los que grandes corrientes emigratorias formarian tropel, llevando a espaldas de sus caravanas el peso de una historia milenaria y una tradición que hace chispas en el alma de los mismos insensatos.

La potencia atlántica los arrastraba sobre espaldas de las olas a través de un mar inmenso, propicio a la hazaña, en que podrían templar sus muslos endurecidos en la lucha fragorosa. Eran aquellos navegantes fuerzas geológicas que iban al encuentro de unos dioses asombrados por el arrojo humano. $\mathrm{Y}$ el mar, indómito y tremendo, aplacó su furia milenaria, terminando por rendirse, humillado al peso del hombre, del mismo modo que, años después, el rayo mismo, verdadero azote de los pueblos, instrumento guerrero de dioses sin entrañas, tornaríase dócil ante el dictado del ser humano. Murió allí el temor, sin gloria y sin provecho. En la empresa, que la fe guiaba, iba implícita la bravura de una raza de gigantes que al vaivén de carabelas diminutas herían con fiereza la dura piel de los mares y lo 
sometían con férrea mano a su voluntad y sellaban una paz de fortaleza con la adversidad y las potencias naturales.

Rota a pedazos Europa en tremendas luchas entre el principado y la soberanía popular naciente, mientras se levantaban hogueras en todas sus poblaciones y la tierra toda rezumaba sangre por sus cuatro costados, la raza ibérica lanzóse mundo arriba a la búsqueda de horizontes para la paz. Simultáneamente, una vez que las mesnadas de mercenarios lanzadas por la nobleza y el papado iban abandonando los poblados indemnes derruídos. aniquilando la purificada beatitud del brazo creador ya en franca rebeldía, tras el sarraceno pasaba el héroe manchego, sazonando la tierra con su humanitarismo, con palabras que aún estamos escuchando, y preparaba la tierra fecunda en la que sembró la semilla de una nueva moral. Elaboróse allí el nacimiento europeo con una conciencia hasta entonces desconocida para el hombre, mancillado por la brutalidad de las hordas que un régimen secular arrojaba sobre las pasiones, los sentimientos y el leve destello de un ideal que surgía dotado de todas las virtudes.

$\mathrm{Y}$ aquellos nautas que asombraron a Europa hasta hacerla estremecer por sus proezas, y avanzaban resueltos a través de nuevas rutas oceánicas por ellos abiertas a la civilización, fueron la guardia europea y su salvaguardia. De uno a otro confín rasgaron el misterio de todos los mares, dejando tras sí una estela luminosa que aún, pasados los siglos, aparece refulgente en todas las aguas y han torcido el destino secreto de los hemisferios, sumidos en la penumbra de lo desconocido, que ingenuas leyendas de la Edad Media poblaran de monstruosos dragones, ávidos de crueldad.

Pueblo de nautas, los lusiadas, descendientes de los fenicios y como ellos marinos de aventura y audaces al extremo, seducidos por el ancho mar que los incita, crearon un mundo dentro de otro mundo, e igual que sus hermanos, también ibéricos, son para el humano una promesa de paz y futuro de libertad.

Fabio Luz es heredero directo de esta estirpe valerosa y generosa que en el Brasil fructificó hasta lograr, en el corto período de doscientos años, formar un núcleo humano dentro de una superficie terrestre que representa la tercera parte del continente. Había nacido el 31 de julio de 1864, en Valença, ciudad industrial de Bahía, para ocupar con el correr de los años un lugar prominente en la literatura de su país. 
Tolstoiano en su vida y arte, el paisaje de su ciudad natal, sobre todo, está pintado con mano maestra en toda su obra, desde la fantasía juvenil hasta la más exigente nota de colorido.

II

\section{Influencia del paisaje}

Seno de Abraham ha llamado alguien a Bahía de Todos los Santos, ciudad y Estado brasileño de su mismo nombre. La historia se ha encaprichado en no darnos el origen en este caso de tan hermoso calificativo, encomendándoselo a la literatura de la región, en que muchos de sus ilustres hijos descollaron. Seno de Abraham, lugar edénico donde el hijo de la tierra se nutre y alcanza la satisfacción en toda la amplitud, sólo concebible en poesía; tierra madre amerosa del hombre, clima que trueca páramos en vergeles, donde la exuberancia llega a lo inimaginable.

Probablemente la benignidad de esta tierra y la fama de prodigio adquirido, indujo, en años que la historia mandó al archivo, a los primeros colonizadores lusitanos a convertir este suelo en centro de sus actividades en el continente poco antes descubierto, hasta otorgarle después honores reales de capital del imperio brasileño, cual to fué durante muchos lustros. Lo que de todo aquello ha quedado en pie para los hombres de hoy, se reduce a un cerco de castillos de estilo medieval en ruinas y algunos monasterios que la tienen aprisionada y vigilan con recelo, pasmados frente al tiempo ido y avocada a la realidad del progreso incesante que la remoza sometiéndola a la férrea disciplina del acero y cemento armado.

Ciudad imperial por excelencia, dueña en un tiempo del poder vital que se extendía a través de soledades inmensas. Bahía de Todos los Santos vive, a pesar de todo, en un ambiente de nobleza. Poderosas razones le asisten para mantener en alto este orgullo, este pendón, pues que ha dado nacimiento a una nación que emerge presurosa a través de los años y se incorpora con sus adelantos al ritmo acelerado de sus hermanas del continente. $Y$ por mucho que otras ciudades y capitales de Estado pretendan emularla, Bahía, ciudad real e imperial, dueña y señora de un nombre cargado de glorias, descansa tranquila, sentada al borde de un océano que la tradición 
poblara de fenómenos extraños y ve cómo las aguas inquietas procedentes de lejanos mundos se sienten heridas por grandes trasantlánticos que son una promesa de futuro, satisfecha de su destino. Bahía de Todos los Santos es un museo de la historia brasileña. De alli arranca la tradición nacional. Es alli donde aparecen los primeros balbuceos del progreso que todo lo trasforma, en pos de una juventud eterna entre los hombres y los pueblos.

Su historia remóntase a los primeros tiempos del descubrimiento, ya que, luego de la aparición del continente, sus tierras soportaron el peso de la raza latina, donde inmediatamente dejaron huella profunda. Los primeros habitantes de aquellos lugares han sido los tupins, que derivan de tup y manquins, poseedores de aquellas tierras, desde el Morro de San Pablo hasta Porto Seguro. Estos fueron sustituídos por los aymorés, de Ilheos, y sus parientes los guerens. El primer habitante civilizado de aquellos contornos fué Sebastián de Pontes, ricachón de origen portugués, señor feudal, dueño de dos grandes ingenios. Levantó un castillo en el morro denominado Outeiro do Rey, que convirtió en centro administrativo de sus inmensas riquezas.

Según la leyenda, parece que el mismo Pontes pretendió coronarse rey de aquellas inmensas soledades, lo que despertó el celo de la corte portuguesa, y tanta irritación provocó esta actitud que luego de su intento fué apresado, cargado de grillos y conducido en un navío de guerra hasta Limoeiro, Portugal, donde quedó sepultado para siempre. Con la retirada forzosa de Pontes las tropelías de los bárbaros guerens y tapuyas, de la nación de los aymorés, se renovaron en forma alarmante. Habiendo éstos logrado expulsar a los pacificos tupins, el elemento humano de que Pontes se servía para erigir su reinado, los colonizadores, conscientes del peligro que aquellas tribus suponían para sus vidas, presentáronles combate a fondo, del que salieron victoriosos. Derrotadas las tribus en Ilheos, trataron de escaparse a los sertoes, y aquel acontecimiento de armas dió comienzo a la edificación en diversos lugares de tierra firme, que les permitiera preservarse de ataques similares. Pero la calma llegó solamente después de una expedición de paulistas que, bajo el comando del práctico Juan Amaro y el gobernador Alexandre de Souza, se internó en el sertao y destruyó algunas tribus, en cuya acción, luego "de cruel carnicería tomó prisioneros ochocientos indígenas". 
Sin embargo, el encono de las razas aborígenes hacia el conquistador tenía raíces tan profundas que la lucha hubo de persistir durante un siglo, si no en forma continuada, al menos esporádica, pero lo suficiente para mantener en plena inquietud a los nuevos habitantes de aquel suelo humífero y prodigioso. Tan es así, que entre los años 1750 y 1754 el estado de guerra se ha agudizado hasta librarse verdaderas batallas.

Presbíteros oriundos de Italia habían fundado una pequeña aldea, a la que dieron el nombre de Una porque estaba sentada al margen del río del mismo nombre. Merced a una política perspicaz y al entendimiento entre un caboclo pacífico y un salvaje, habíase dado fundamento a aquel pequeño poblado. Esta circunstancia hizo que momentáneamente la contienda entre los salvajes fuera resuelta, y así dicha aldea fué el comienzo del Brasil en aquellos contornos al ofrecer una era de paz, quedando lazos de amistad aún más apretados luego que uno de los salvajes fué víctima de castigos y expulsado de su tribu, yendo luego en procura de refugio y amistad entre los blancos. Valiéndose de este acontecimiento, los presbíteros italianos consiguieron conquistar la simpatía del caboclo Adán, oriundo de la tribu de los antiguos guerens, armonizando con los habitantes de la tribu que estaban acampados a leguas de distancia, hasta lograr someterlos a los nuevos métodos de vida. Pocos adultos lograron resistir la experiencia, pues los alimentos a que no estaban habituados provocábanles disenteria, denominada por ellos camares de sangre; sin embargo, algunos niños resistieron el procedimiento de adaptación y las nuevas mujeres, la madre, que es el único baluarte inexpugnable de la historia y elemento de privilegio que todas las guerras no han podido exterminar, ya en la paz, el pequeño núcleo fué en aumento hasta dar nacimiento a la ciudad. Otro Adán había creado un nuevo paraíso. De ahí proviene, según la leyenda, el denominativo de seno de Abraham.

Antonio de Padua de Goes facilita un hermoso asunto para la reconstrucción histórica de la colonización del sud de Bahía. Sin contar la parte de santidad que este presbítero puede tener, icuánto hay por estudiar respecto a aquel período colonial! Es de alli de donde arranca lo que hoy conocemos de todos estos pueblos que nos hablan de luchas tremendas, desde los asaltos de los salvajes a las haciendas del Jordán de Jequié, la heroica resistencia de los colonizadores e inútiles sacrificios de los más osados, derroche de abnegación 
y coraje, fanatismo de los colonos invasores, batallas contra los primitivos señores de aquellas tierras incultas que defendían con ensañamiento feroz y salvaje.

Las dos ciudades más importantes de Bahía son Salvador y Valença. Salvador adquirió la gloria de ser el centro universitario del país en su pasado histórico. Múltiples generaciones de hombres formáronse en sus casas de estudios. Con las investigaciones que de allí surgieron, alimentóse una cultura propia por espacio de muchos lustros y que con el correr de los años crearía héroes y sabios que formarían la conciencia nacional, muchos de ellos incorporados a la historia del país. Del progreso experimentado en las ciencias y artes de aquel centro, da idea el acontecimiento de distinguirse con rasgos precisos una literatura bahiana propiamente dicha ya en el siglo xvir. De esta generación es fray Vicente Salvador, que a principios del siglo xvI escribiera una admirable Historia del Brasil, monumento de estilo y senso crítico que ennoblece la historia literaria de la nación y le da categoría en sus artes. Aparecen en esa misma época el padre Antonio Vieira, conceptuado como el mayor orador sacro en lengua portuguesa, y Gregorio de Matos, creador de la poesía brasileña que, junto con Manuel Botelho, darán vida a una pléyade de escritores y poetas gloriosos en aquella era de fecundidad y juicios privilegiados.

Generaciones posteriores fueron el caldo de cultivo de que múltiples genios se nutrieron, elevando la cultura del país a un nivel equiparado con el progreso que alcanzó en otros lugares del continente. Bahianos, para mencionar sólo algunas de sus figuras más prominentes, fueron el canciller del imperio, Zacarías de Goes y Vasconcellos, que tan alto puso ante el mundo el ideal de su nación. Lo era Castro Alves, el poeta épico del país, considerado como el Espronceda brasileño, y que tanta influencia ejerció en aquella revolución que culminaría con la abolición de la esclavitud. Otro poeta magnífico, José Alexandre, también era bahiano, así como el segundo Castelar, Ruy Barbosa, ave canora por su verba floreciente y el alto sentir de su pensamiento. Lo eran también los hermanos Lopes dos Santos Luz: Zacarías, canónigo, monseñor, profesor de latín, orador sacro y poeta delicado en sus momentos de ocio, cuya producción se halla dispersa en la prensa, en publicaciones que datan de medio siglo atrás, y Fabio, el alma grande, dotada de todas las cualidades que la naturaleza imprime a los predestinados; humanista en el más amplio sentido de la palabra, cuya "pluma honesta y limpia fué su 
martirio y su gloria", en opinión del poeta Leoncio Correa. Son nacidos en Bahía los escritores Xavier Marques y Jorge Amado, dos glorias de la literatura contemporánea en el continente americano y hasta en Europa, por no decir en el mundo, pues su producción está traducida a varias lenguas.

En idéntico pie de igualdad que Salvador en el orden cultural del Brasil, se halla la ciudad de Valença con sus florecientes industrias. Salvador es el centro de donde emerge, pujante, la fuerza moral de la nación, creadora en este orden de hijos ilustres, ya incorporados a la historia universal algunos de ellos, por su espíritu de contracción, por su capacidad, por su genio. En cambio, Valença es el centro vital donde se plasmarán prácticamente algunas de las enseñanzas adquiridas en Salvador. Valença encarna el progreso industrial del país y se enctentran así entrelazadas estas dos ciudades que se abren al futuro con una promesa de grandes esperanzas: son lo abstracto aplicado a lo práctico. De ciudad industrial fué el título otorgado por el imperio y el destino ha querido que dos de sus fábricas de tejidos ya históricas continúen funcionando, la "fábrica de arriba" y la "fábrica de abajo", movidas a presión hidráulica, nadando sobre la corriente que descansa en el océano, en la misma desembocadura del río Una. Un comercio importante ejercía la ciudad a principios del siglo pasado, particularmente de productos del país, y de ello le quedan vestigios en nuestros días como reminiscencia de aquellos tiempos. Estos han sido los dos brazos potentes en que se ha fincado el progreso brasileño; de alli arrancan sus energías en este crear incesante de pueblos y ciudades que la evolución empuja como una consecución imperiosa de los tiempos civilizados.

\section{III}

\section{El hombre y el escritor}

Ha sido contemplado todo este pasado de glorias y triunfos, este paisaje natural que la historia y la flora presentan a los ojos del hombre-poeta, esta creación magnífica de hechos, que revelaron a Fabio Lopes dos Santos Luz como creador a su vez, como constructor de una obra de recompensa a la que consagraría lo mejor de su vida. La descripción del paisaje y la magnificencia de tanto acontecimiento, en cuyo ciclo evolutivo se han empleado casi dos siglos de luchas 
tremendas hasta lograr imprimirle los rasgos típicos de una nueva civilización, le han convertido en artista. Y no tanto por los hechos de armas, a los que toda la historia humana enajenó su fuerza moral, sino por el cúmulo de voluntades y energías empleadas para la prosecución y consecución del amanecer histórico de aquel país. Todo aquello golpeaba a su corazón y le llamó con palabras de acento especial, al extremo que, aun escritor de múltiples facetas, y médico que hizo de su profesión un sacerdocio, no ha podido sustraerse al medio histórico en que viviera su infancia. Es esta una particularidad que eleva su obra de medio siglo a la categoría del maestro; él ha sabido arrancar del pasado las fuerzas necesarias que dan a su obra la savia vivificante y siempre floreciente, henchida del más puro humanismo.

El propio Fabio Luz, muchos años después, expresaría que el muelle protegido por la isla Tinharé, limitado por las islas Cayrú y Boipeba, se le aparecía cruzado en todos los sentidos por lanchas y veloces remolcadores. La pequeña corriente del río Una, de difícil navegabilidad, lleno de bancos de arena movediza, de pequeño volumen de agua y reducida extensión, tenía para él, cuando se inició en las letras, la impetuosidad del Amazonas y la potencialidad del Mississippi. Pero la imaginación dispensaba el concurso del río, trecho ornamental en el paisaje que trastrocaba la ciudad en emporio industrial y comercial, pues oía, en el futuro insondable, el ruido ensordecedor de las fábricas, soplando humo por las altas chimeneas, y auscultaba la pulsación de una estación ferroviaria, poniendo aquel centro en contacto con el lejano sertón lleno de canciones y heroísmos desconocidos, y con el litoral, al norte y al sur, ligando en solidaridad tierras y poblaciones desde Nazareth hasta Canavieiras.

Cuando pienso en aquellos sueños, agregaba, que se desdoblaban en una esperanza de continuo progreso, ríome de mí mismo, evocando la figura del soñador que desfilaba contento entre los compañeros de colegio. Y bajo la mirada complaciente del maestro, tan contento como cualquiera de nosotros, cuchicheábamos haciendo travesuras o pensando en paseos o excursiones. $\mathrm{Y}$ yo gozaba la dulce ventura de libertarme por algún tiempo de las respuestas breves y familiares del padre Segur, de las complicaciones de la gramática y de las impertinencias de la aritmética. Ya preveía el incomparable placer de los días seguidos e ininterrumpidos pasados en inefable alegría junto 
a mi querida madre, escuchando sus cuentos y consejos, acompañándola en las labores domésticas, interrumpiéndole el trabajo diario. Eran aquellos días de correrías, robando frutas, subiendo a los árboles para coger nidos. Por la mañana, al aire fresco, embalsamado de perfumes selváticos, las largas excursiones a través de los naranjales y campiñas, mojando los pies descalzos en el rocío goteante de las hojas, en la travesía de los regatos en busca de fruta o en procura del lecho más hondo de la corriente donde nos regalábamos en retemplado baño.

Pero no siempre me fué dado gozar de la libertad completa concedida a mis hermanos. Largas enfermedades me prendieron al lecho por días interminables. Sufrí enormemente en recaídas sucesivas, con rápidas intermitencias de salud. $Y$ eso me hizo soñador. Preso al lecho, en la agitación tremenda de todos los músculos de la vida de relación, en el desorden y en la imposibilidad de coordinar los movimientos, su cerebro trabajaba más de lo que era natural a su edad. Aquella enfermedad sutilizó su fantasía y, siendo desconocida en la localidad, hizo que todos sintieran conmiseración por su padre, a quien el destino le había reservado la desgracia de tener un hijo idiota, que a los setenta y cuatro años de edad había de tener escritos dos docenas de libros en que está encerrado todo el amor, la dulzura e inmensidad del alma humana.

Cuando estaba para recibirse de bachiller, un negociante amigo, muy condolido, le preguntó cierto día si todavía vivía su hermanito enfermo, del que nada más se había oído hablar. "Aquel niño enfermo era yo. ¡Cuánto por mí has sufrido, madre querida!... Te veo todavía. en la tardecita, habiendo formado un medio círculo al claror de la estrella vesperal, enseñándonos, con tu voz melodiosa, un poco apagada, «El ángel del Señor»..., que en la dulce melancolía del atardecer parecía haberse encarnado en ti, tan santa y amorosa.

"Cuando en mi edad estos recuerdos volaban de tal modo, vivos y claros, no es posible olvidarlos, aun olvidados, aquellos lugares donde nací y que tanto me hablan de todo lo que amé, de todo lo que sufrí en los primeros años de mi vida inútil, hoy en camino del fin. La tierra, la casa, los ornatos interiores de la familia que se dispersó para formar sus diversos nidos en una emigración en busca de mejorar su suerte, todo cuanto forma parte de nuestra vida pasada en común, en el hogar paterno, todo revive intensamente en la memoria con 
amor y cariño. Este sentimiento de solidaridad que se forma y robustece en el rincón hogareño, no es patriotismo, sino solidaridad. Toda la autoridad y toda disciplina ostensible, matan el sentimiento y provocan revueltas. Por mí mismo sé que el amor no conoce leyes: o salta por encima de ellas o no es amor si se somete. Si estuviera sujeto a leyes civiles y a prescripciones de códigos, antes que nada sería una penalidad impuesta, en detrimento de la libre manifestación del querer o del ođiar, sería una imposición tiránica y no una ley natural."

IV

A los 16 años de edad Fabio Luz se trasladó a la capital del Estadó, matriculándose en el Liceo Provincial en virtud de haber llegado tarde para someterse a los exámenes preparatorios. Allí repitió el curso, ya hecho en Valença, contando como profesores, a partir de este año en que debió repetir el curso, al cura Fiuza, latín; Carneiro Ribeiro, portugués; Luis Filgueiras, geografía; Franco Meirelles, eximio traductor de El Paraíso Perdido, de Milton, inglés, y Moreira Sampaio, francés. Sustentados en 1891 los cinco primeros exámenes, en 1892 completó el curso de humanidades. Sus profesores fueron: de matemáticas, el conocido maestro Tantú, por cuyas manos pasaron generaciones de estudiantes; de filosofía, el doctor Sebastián Carvalho; de historia, el profesor Odorico O. Odillón. Desde 1883, fecha en que se matriculó en la Facultad de Medicina de Bahía, hasta que obtuvo el doctorado, contó siempre con calificaciones sobresalientes en todas las materias y fué objeto de una distinción especial por su tesis Hipnotisno y libre arbitrio, al ser graduado en medicina.

Aplicado a la lectura desde su más tierna infancia, germinó en él un afán inveterado de querer conocerlo todo y su amor por el estudio ha persistido hasta el último momento de su vida, en que "cayó como un héroe en el campo de batalla, manejando la pluma como otros blanden la espada, esa pluma honesta y limpia que fué su martirio y su gloria", como dijera Leoncio Correia.

Desde sus tiempos de estudiante tenemos colaboraciones dispersas, en el periodismo local, especialmente en la Gaceta de Valença, 
que perfilaban el futuro escritor de recia contextura moral, definido en toda su grandeza en Hipnotismo y libre arbitrio. Su tesis de doctorado ha sido un programa de labor futura, en el orden literario, en lo moral y social. Rompe las primeras lanzas, que luego encenderán chispas durante medio siglo de vida literaria y de actividad en pro de una constante revolución. Este folleto es el antuncio del futuro sociólogo, al que ningún problema social le era ajeno. Así, afirmó entonces, comenzando por el hombre, persona social, que "entre dos motivos de fuerza diferente, éste decidiese por el más fuerte, por el menos perjudicial a su vida y a sus intereses. El perfeccionamiento del senso moral depende del desenvolvimiento intelectual de cada nación. La ley que despanzurra al asesino y al malhechor, no se distingue del cazador que mata al lobo para impedir que lo perjudique y para ahuyentar la horda invasora", pero sus resultados son contraproducentes. "La libertad consiste en poder seguir sin obstáculos las leyes de nuestro propio ser, pero de ningún modo está en dic tarlas o dirigirlas." Herzen ha dicho que "la libertad significa solamente ausencia de obstáculos exteriores o interiores, psíquicos o físicos, intelectuales o morales". Con este caudal ideológico, Fabio Luz adelántase a los principios sustentados años después por Guyau, respecto al hipnotismo como elemento de educación y regeneración humanas, que le convertirían en un genio en el campo de la sociología.

Pero esta forma de pensar de Fabio Luz tiene mayor importancia todavía al observar que la edad iba madurando sus conceptos, perfeccionándolos, $\mathrm{y}$ toda su vida ha sido un verdadero laboratorio intelectual. $Y$ cobran doble valor estas sentencias de su juventud, por cuanto significan una promesa harto cumplida hasta el instante de su muerte. Su figura adquiere relieves más prominentes si tenemos en cuenta que no ha habido en él un desfallecimiento, una duda siquiera, aun en los momentos más críticos de su vida. Ahí están cincuenta años de historia nacional encerrados en sus crónicas que el periodismo se encargó de esparcir y en las que nadie hallará una sola línea, una sola palabra que denote el menor decaimiento. Veinticuatro volúmenes en que está condensado lo más selecto de su prosa y que abarca todos los géneros literarios son testimonio de una labor gigantesca y constante, de donde afluye el más puro humanismo, en toda su grandeza espiritual. 


\section{Permanencia de su arte}

La labor literaria de Fabio Luz ofrece un caso típico de perseverancia y alta categoría. Los elementos de que dispone han sido arrancados de la misma fibra nacional. Enamorado de la belleza, logra imprimir a su obra toda la exuberancia y dulce sabor de melodía. En su prosa delicada consiguió apresar la riqueza del ambiente, fundiéndola con la grandiosidad de aquel pasado histórico en que se deshace el alma de una humanidad que comienza y promete abrazar la tierra e infundirle el don de la ternura.

La obra de este escritor hay que apreciarla en conjunto, dadas las múltiples facetas que abarcó, desde la novela hasta el estudio sociológico. Mas para observar toda su grandeza espiritual, cualquiera de sus estudios sirve de elemento para enjuiciarlo sin equivocación, pues que en todos está impresa la huella imborrable de la fe, de su gran amor a lo sublime. Las directrices que se había trazado en su primera producción Novellas, conducta seguida en forma constante y sin desmayos hasta. Holofernes, su último libro, dan idea de una inquebrantable convicción que bajo aquellos impulsos, aquel mismo sentir y aquella concepción estética, seguirían siendo el sueño dorado de toda la vida. El primero de los libros mencionados tiene el significado de una profesión de fe; el segundo es su propia confesión. Caso curioso, no obstante: de uno al otro no existen diferencias fundamentales en la apreciación artística, ni siquiera en pensamiento. Sus personajes hablan con la lozanía de la juventud y en una lengua que cada uno de los mortales quisiéramos para nosotros, con una limpidez de estilo y hermoseada de pensamientos cual sólo conocen los maestros en este arte.

Ideólogo, otro de sus libros, abrió las puertas a un nuevo mundo literario que serviria de modelo a generaciones posteriores. Profundo conocedor de humanidades y gran estudioso durante toda la vida, Fabio Luz trasplanta a otro continente las inquietudes, sinsabores de raigambre profunda que, dentro de la incomprensión de nuestro mundo moral, fuera angustia y martirio de Tolstoi. Una veintena de volúmenes encierran parte de su producción, que no representa la mitad de su labor desperdigada en publicaciones de lengua portu- 
guesa. Habiendo ensayado sus primeras armas en la prensa de Valença a la temprana edad de 20 años, a los 74 su jugosa pluma continuaba destilando líquenes esparcidos en la prensa del país, Francia, España y América del Norte. Solamente su obra de crítico literario enjuicia medio siglo de historia brasileña; sus ya famosos rodapés analizan las incoherencias así como las virtudes de aquel pueblo donde quedan impresas las inquietudes de generaciones que Fabio Luz condujo, llevadas de la mano, y con ojo vigilante fué siguiéndolas hasta el resto de sus días.

En toda esta labor gigantesca es el paisaje el que predomina y fascina, frena sus arranques de escritor y le troca en poeta de la naturaleza. El paisaje en el cuento, en la novela y en el romance, dice todo cuanto sobre él pesaba el influjo de atracción de aquellos elementos que absorbía y vivía diariamente. Es éste un libro único en su género, cual lo son sus Estudios de Literatura. En aquél se estudia la influencia que a través de la historia el elemento natural, el medio, ejercen sobre el hombre, hasta terminar por atraerlo hacia sí y convertirlo en débil componente de la gran armonía universal; en éste, sucesión continuada de los anteriores estudios, demuéstrase cómo la humana persona lleva en su interior una parte de artista, desde la concepción del mundo moral al mundo natural. Ambos libros se complementan. Es la historia y el paisaje, cuyos primeros destellos pudiera percibir en Valença el pequeño huérfano, contemplando el inmenso océano que venía de mundos antiquísimos, cansado de glorias. Ideólogo abre un nuevo ciclo literario en el país, del que surgieron nuevas corrientes literarias. En este libro perfílase el escritor de enjundia con rasgos particularísimos. Han debido pasar cerca de veinte años para que tal novela adquiriera la importancia a que es acreedora dentro de las letras portuguesas. Porque los personajes de Fabio Luz son brasileños, como brasileña es su factura literaria. El no ha tenido necesidad de recurrir a otras literaturas en procura de elementos para sus creaciones, ya que los tenía al alcance de la mano: el paisaje y su centro moral, el cuerpo y el alma humanas que, cual arcilla, encontraron su propio artífice.

Su obra es su monumento. Páginas ha escrito que son un modelo en su género, tanto en escritos didácticos, incorporados a la enseñanza oficial, como en los múltiples temas que ha tratado. En todos ellos prima la descripción como fruto de sus mejores ilusiones, y la historia, aquel pasado imponente, Valença, Bahía de Todos los 
Santos, seno de Abraham. Un último viaje a los lugares paternos le hizo rememorar toda aquella grandeza espiritual que le embargara, porque de allí naciera la nación y la nacionalidad; de allí partieron los primeros balbuceos de la independencia y la revolución después, con su gran dosis de humanismo. Habían sido aquellos lugares los que infundieron un alma al esqueleto nacional: allí sintió en pleno rostro la caricia suave del arte y descubrió que también él era elemento útil a la humanidad por ser uno de sus componentes, y de allí, una vez comprendidos los secretos de todo lo que le rodeaba, advino la admiración y creación de una obra gigantesca, hasta que la vida se le extinguió el 9 de mayo de 1938.

Campio Carpio 
